\title{
Clinical Profile and Outcomes of Angiographic Severity in Patients with ST Segment Elevation Myocardial Infarction with Reciprocal ST Segment Depression
}

\author{
Md. Magfur Rahman ${ }^{1 *}$, A. K. Al Miraj ${ }^{2}$, H. N. Ashikur Rahaman ${ }^{3}$
}

${ }^{1}$ Cardiac Surgeon \& Consultant (Cardiologist \& Diabetologist), Department of Cardiac Surgery, Bangabandu Sheikh Mujib Medical University (BSMMU), Dhaka, Bangladesh

${ }^{2}$ Research Assistant, Department of Vascular Surgery, Bangabandu Sheikh Mujib Medical University (BSMMU), Dhaka, Bangladesh ${ }^{3}$ Registrar, Department of Clinical Oncology, Enam Medical College \& Hospital, Savar, Dhaka, Bangladesh

*Corresponding author: Md. Magfur Rahman

Abstract Original Research Article

Background: The importance of reciprocal ST segment depression throughout acute infarct has been a region of dialogue, whether or not it's a symptom of multivessel unwellness, ischemia at a distance or just a benign physical phenomenon. Objective: To find out the Clinical Profile and Outcomes of Angiographic Severity in Patients with ST Segment Elevation Myocardial Infarction with Reciprocal ST Segment Depression. Patients and Methods: The current study was conducted as a prospective, controlled single center study involving two hundred patients with ST elevation Myocardial infarction who were admitted to the Department of Cardiac Surgery, Bangabandu Sheikh Mujib Medical University (BSMMU), Dhaka, Bangladesh and had undergone coronary angiogram with PCI result in the Clinical Profile And Outcomes of angiographic severity in patients with ST segment elevation myocardial infarction association with reciprocal ST segment depression period between January 2018 and December 2018. Two hundred ST elevation infarction patients (100 inferior, one hundred anterior), every cluster was sub-grouped into a pair of subgroups consistent with the presence of reciprocal ST segment depression or absence: in anterior STEMI cluster we have a tendency to had subgroup A1 with RSTD (41 patients) and subgroup A2 while not RSTD (59 patients) whereas in inferior STEMI cluster every sub-group (B1 and B2) consisted of fifty patients. Coronary angiography was done in all patients within 15 days of acute ST segment elevation with RSTD or non-RSTD having including primary PCI, thrombolytic therapy and SC LMWH. Results: This study was Patients with reciprocal ST segment depression showed a significant lower mean Left ventricular ejection fraction compared to those without $(37+3 \%$ vs $53+5 \% \mathrm{P}<0.001$, anterior ST elevation myocardial infarction subgroups) \& $(47+4 \%$ vs $60+3 \% \mathrm{P}<0.001$, inferior ST elevation myocardial infarction sub-groups). Multivessel disease was higher incidence of found in subgroups with reciprocal ST segment depression $(80.5 \%$ vs $49.2 \%, \mathrm{P}<0.001$ in ST elevation anterior myocardial infarction) \& $(60 \%$ vs $20 \%$, P < 0.001 in inferior ST elevation myocardial infarction). The mean gensini score was modified higher in subgroups with reciprocal ST segment depression $(64.2+12.6$ vs $30.2+6.6, \mathrm{P}<0.001$ in anterior infarction group) \& $(36.2+10.6$ vs $20.4+4.2, \mathrm{p}<0.001$ in inferior infarction group). Conclusion: Reciprocal ST segment depression in acute myocardial infarction associated with significant LV systolic dysfunction \& coronary artery disease of greater extent.

Keywords: Reciprocal ST Depression, ST Elevation Myocardial Infarction, Modified Gensini Score.

Copyright $\left({ }_{0} 2021\right.$ The Author(s): This is an open-access article distributed under the terms of the Creative Commons Attribution 4.0 International License (CC BY-NC 4.0) which permits unrestricted use, distribution, and reproduction in any medium for non-commercial use provided the original author and source are credited.

\section{INTRODUCTION}

Among a lot of examinations performed in the Acute Myocardial Infarction (AMI) setting, the electrocardiogram (ECG) remains the broadly acknowledged and effectively done test for the diagnosis [1]. The ECG changes reflect the picture of the affected myocardial territory [2]. Reciprocal ST Segment depression (RSTD) is a typical ECG finding frequently going with ST segment myocardial infarction
(STEMI). The ST depression may point to ischemia in a myocardial area other than the zone of infarction or may represent merely a benign electrical phenomenon. There is bottomless writing concerning the hugeness of various sorts of ST depression in STEMI [3]. In anterior myocardial infarction, ST depression encountered in inferior leads might be corresponding to contribution of the basal anterolateral region supplied by the first diagonal branch and observed as ST segment elevation 
Magfur Rahman et al; Sch J App Med Sci, Feb, 2021; 9(2): 283-290

in leads I and aVL [4]. Myocardial infarction is the term applied to myocardial necrosis secondary to acute interruption of coronary blood supply [18]. The earliest changes seen with an acute transmural infarct are usually in the ST-T complex [19]. In acute transmural infarct, ECG shows typical ST segment elevation (termed"indicative" changes) in the leads facing the area of infarction. Apart from these ST segment elevation change $s$, the leads remote from the area of infarct often show ST segment depression, which is not always present even when the ST elevation is extreme. Again when reciprocal ST segment depression is present, it does not always have the same time course as the ST segment elevation. This observation makes the issue more controversial [20]. Reciprocal ST-segment depression during acute myocardial infarction is a common finding occurring in about 54-82 \%. Although such ST segment depression reflecting there mote non infracting myocardial wall was described 49 years ago, the pathogenesis of such electrocardiographic changes still remains controversial. The aetiology and significance of these reciprocal ST segment changes has been the subject of several conflicting reports over the years [21]. In patients with inferior myocardial infarction, the presence of ST segment depression in lead $\mathrm{I}, \mathrm{aVL}$ is a reciprocal change and is found in nearly all patients [5], while ST depression in leads V1-V3 most likely does not imply" "ischemia at separate zone" yet rather reciprocal changes [6]. Interestingly, among patients with inferior STEMI, ST segment depression in leads V4-V6 is linked with associative left anterior descending coronary stenosis or three vessel disease representing ischemia at a distance [7].

\section{Material ANd Methods}

The current study was conducted as a prospective, controlled single center study involving two hundred patients with ST elevation Myocardial infarction who were admitted to the Department of Cardiac Surgery, Bangabandu Sheikh Mujib Medical University (BSMMU), Dhaka, Bangladesh and had undergone coronary angiogram with PCI result in the Correlation of angiographic severity in patients with ST segment elevation myocardial infarction association with reciprocal ST segment depression period between January 2018 and December 2018.

\section{Inclusion Criteria}

- The study enclosed patients diagnosed to own either acute inferior wall infarction or acute anterior wall infarction [ECG was recorded on admission and unconcealed changes of acute infarction i.e. ST phase elevation P1 millimeter in a minimum of 2 adjacent leads representing either the inferior wall (leads II, III, I, aVF) or 2 millimeter the anterior wall (V1-V6, aVL) in conjunction with typical hurting for a minimum of thirty min and up to twelve $h$ length cardiac biomarker (Troponin) and a rise in viscus enzymes to quite doubly the traditional value]. The designation of STEMI was then confirmed throughout coronary X-ray photography by process the perpetrator lesion (the thrombotically occluded infarct-related vessel) that was after revascularized throughout the procedure.

\section{Exclusion Criteria}

- Patients with STEMI who were subjected to undergone PCI and had an intra-procedural complication or absence of angiographic or procedural success were barred from the study (to avoid the confounding impact of procedural complications on the in hospital outcome that may interfere with the point of interest of evaluate only the impact of RSTD).

- Other exclusion criteria were: left bundle branch block(LBBB), associated intraventricular conduction disturbances, right ventricular infarction, posterior infarction (diagnosed by horizontal ST depression, tall broad $\mathrm{R}$ waves $>30 \mathrm{~ms}$, upright $\mathrm{T}$ waves and dominant $\mathrm{R}$ wave i.e. R/S proportion $>1$ in $\mathrm{V} 2$, paced ECG rhythm\& patients with disseminated malignancies.

\section{Data Collection}

We recorded data on age, sex, history of diabetes mellitus, history of essential hypertension, the presence of dyslipidemia, positive family history of coronary artery disease \& any comorbidity (cerebrovascular accidents, chronic kidney disease, liver disease, COPD or bronchial asthma).A standard 12-lead ECG was recorded immediately after admission \& the diagnosis of STEMI was confirmed (whether anterior or inferior STEMI). We define Reciprocal ST segment depression (RSTD) as the presence of ST depression $>1$ $\mathrm{mm}$ in at least two out of the precordial leads V1-V6 or $\mathrm{V}_{2}-\mathrm{V}_{3} 0.05 \mathrm{~mm}$ I \& aVL leads (anterior RSTD in inferior STEMI) or ST depression $>1 \mathrm{~mm}$ in the inferior leads II, III, aVF leads (inferior RSTD in anterior STEMI). All the studied patients were subjected to a full echocardiography with special emphasis on the left ventricular ejection fraction (LVEF \%). All patients had undergone coronary angiography to determine the culprit lesion followed by undergone percutaneous coronary intervention (undergone PCI) as the selected reperfusion therapy and the cut-point used to define a significant coronary stenosis was the presence of P70\% coronary luminal stenosis. We also recorded extent (single, two or multi vessel disease) \& severity of CAD using modified Gensini Score [8] which graded the degree of narrowing of the coronary arteries as 1 point for $1-25 \%$ narrowing, 2 for $26-50 \%$ narrowing, 4 for 51-75\% nar-rowing, 8 for 76-90\% narrowing, 16 for $91-$ $99 \%$ narrowing \& 32 for total occlusion. After calculation, the score was then multi-plied by a factor according to the lesion's location in the coronaries (5 for left main disease, 2.5 for proximal LAD \& proximal LCX (3.5 if the LCX is dominant), 1.5 for mid-LAD, 1 
for the distal LAD, 1st diagonal, proximal, mid \& distal regions of RCA, mid \& distal regions of LCX \& obtuse marginal or posterior descending branch, 0.5 for the 2 nd diagonal or posterolateral branch. Finally, the score was expressed as the sum of the scores for the all coronary arteries [8].

\section{ECG Evaluation}

The earliest ECGs obtained were evaluated. Standard 12 lead ECGs were per formed on all the 100 patients during their admission. All ECGs were recorded at $25 \mathrm{~mm} / \mathrm{sec}$. The magnitude of ST-segment deviation was me assured from base line (TP segment). For the diagnosis of acute inferior myocardial infarction, patients should have $>1 \mathrm{~mm}$ of ST- segment elevation (measured $80 \mathrm{~ms}$ after the $\mathrm{J}$ point of QRS complex) in leads II, III, avF. Significant ST depression was defined as $1 \mathrm{~mm}$ or greater horizontal or downward ST- segment depression measured at $80 \mathrm{~ms}$ after J point in le ads V1- V6. The maximal ST- segment elevation in any inferior lead and maximal ST- segment depression in any precordial lead were recorded. The inferior ST- segment elevations were summed and mean was calculated.

\section{Statistical Analysis}

Numerical variables were described as Mean \pm SD. Categorical variables were described as percentages. Comparisons were done using student $\mathrm{t}$ test for numerical variables and chi square test for categorical variables. Value was considered significant if 60.05.The independent contribution of variables was assessed using a multivariate regression analysis. Statistics were calculated using "SPSS" Windows 19 package.

\section{RESULTS}

This study was 200 patients were (44\% females and 56\% males) (Figure-1). The mean age was $51.8 \pm 15.6$ years. 100 patients were admitted with acute anterior wall myocardial infarction and 100 patients were diagnosed as acute inferior wall myocardial infarction. Patients admitted with anterior wall myocardial infarction (group A 100 patients) were further sub-grouped into two sub-groups according to the presence of reciprocal ST segment depression (RSTD) in the inferior leads II, III, aVF (subgroup A1, 41 patients) or absence (subgroup A2, 59 patients). Comparing the two subgroups (A1 \& A2) regarding the baseline demographic \& clinical characteristics, we found that subgroup A1 showed a statistically significant higher prevalence of diabetes mellitus yet there was no statistically significant difference between the two subgroups regarding the prevalence of HTN, dyslipidemia, family history of CAD, cigarette smoking or any other co-morbid illness. There was no statistical significant difference between the 2 subgroups A1\&A2 regarding either pain to balloon time $(55 \pm 22$ versus 52 $\pm 26 \mathrm{~min}, \mathrm{p}$ value 0.74 ) or door to balloon time $(25 \pm 10$ versus $23 \pm 12 \mathrm{~min}, \mathrm{p}$ value 0.66). Regarding echocardiographic data, we found a statistically significant lower mean ejection fraction in subgroup A1 compared to subgroup A2 $(37 \%$ vs $53 \%$, P value $<0.001)$. Echocardiographic evidence of regional wall motion abnormalities (RWMAs) in anterior segments were found in all patients in the 2 subgroups whereas RWMAs in areas of the left ventricle remote from the infarction were seen in the 2 subgroups (A1 \& A2) yet with no statistical difference $(48.8 \%$ versus $50.8 \%$, p value 0.45). All patients in group A (anterior STEMI) were subjected to undergone PCI of the culprit vessel (LAD in $100 \%$ of cases). Each patient included in the two subgroups received a single stent, the length of the stent was selected according to the discretion.

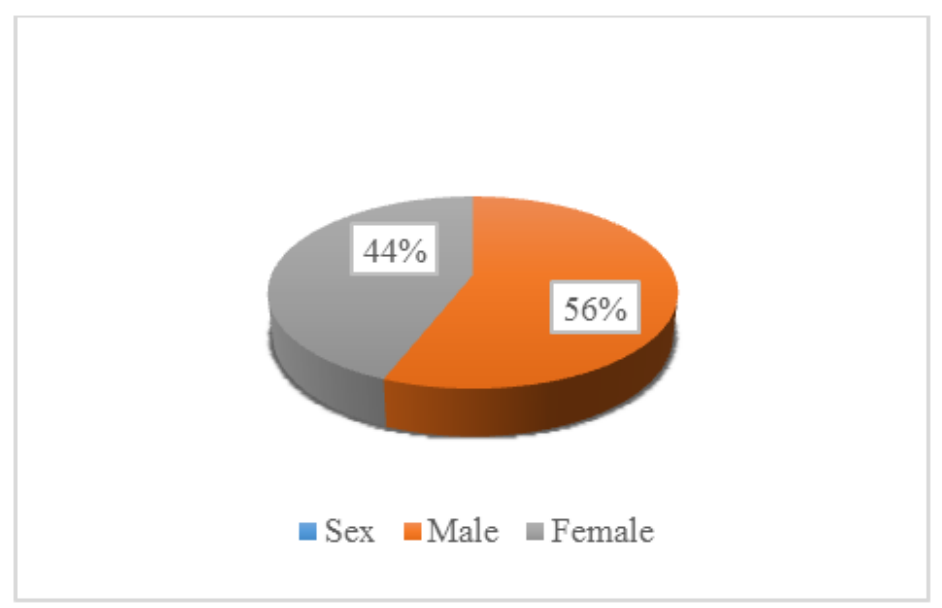

Fig-1: Age distribution of the patients 
Magfur Rahman et al; Sch J App Med Sci, Feb, 2021; 9(2): 283-290

Table-1: Acute anterior wall myocardial infarction (group A) data $(n=200)$

\begin{tabular}{|l|l|l|l|}
\hline \multicolumn{1}{|c|}{ Parameter } & $\begin{array}{l}\text { Subgroup A1(inferior } \\
\text { RSTD), 41 patients }\end{array}$ & $\begin{array}{l}\text { Subgroup A2(no inferior } \\
\text { RSTD), 59 patients }\end{array}$ & P value \\
\hline Age & $53.3 \pm 17$ & $50.3 \pm 14.2$ & 0.331 \\
\hline Male (\%) & $51.2 \%$ & $52.6 \%$ & 0.822 \\
\hline Diabetes mellitus & $73.2 \%$ & $32.2 \%$ & $<0.001$ \\
\hline Hypertension & $53.7 \%$ & $37.3 \%$ & 0.078 \\
\hline Dyslipidemia & $22 \%$ & $23.7 \%$ & 0.412 \\
\hline Family history of CAD & $25.4 \%$ & $26.8 \%$ & 0.522 \\
\hline Cigarette smoking & $64.4 \%$ & $70.7 \%$ & 0.33 \\
\hline History of CVA & $12.2 \%$ & $10.2 \%$ & 0.55 \\
\hline History of renal impairment & $9.8 \%$ & $6.8 \%$ & 0.38 \\
\hline History of chest disease & $19.5 \%$ & $25.4 \%$ & 0.43 \\
\hline Echocardiography:- & & & \\
\hline Ejection fraction (EF $\%)$ & $37 \pm 3$ & $53 \pm 5$ & $<0.001$ \\
\hline Cardiac biomarkers:- & & & \\
\hline Troponin I(ng/mL) & $25.00 \pm 0.00$ & $15 \pm 0.81$. & \\
\hline Angiographic data: - & & & 0.001 \\
\hline Lesion length & $21 \pm 5$ & $24 \pm 6$ & NS \\
\hline Percent stenosis & $95 \pm 5$ & $95 \pm 5$ & $\mathrm{NS}$ \\
\hline TIMI III post PC & $100 \%$ & $100 \%$ & $\mathrm{NS}$ \\
\hline Acute stent thrombosis & $0 \%$ & $0 \%$ & $\mathrm{NS}$ \\
\hline TLR & $0 \%$ & $0 \%$ & $<0.001$ \\
\hline Multivessel CAD & $80.5 \%$ & $49.2 \%$ & $<0.001$ \\
\hline Significant RCA lesions & $75.6 \%$ & $42.4 \%$ & 0.023 \\
\hline Significant LCX lesions & $48.8 \%$ & $27.1 \%$ & $<0.001$ \\
\hline MGS & $64.2 \pm 12.6$ & $30.2 \pm 6.6$ & \\
\hline & & & \\
\hline
\end{tabular}

Table-1 shows we found a statistically significant higher incidence of multi-vessel disease in subgroup A1 compared to subgroup A2 (80.5\% vs $49.2 \%, \mathrm{P}$ value $<0.001)$. There was a statistically higher incidence of significant RCA lesions in subgroup A1 compared to subgroup A2 (75.6\% vs $42.4 \%$, $\mathrm{P}$ value < 0.001 ), higher incidence of significant LCX lesions in subgroup A1 compared to subgroup A2 (48.8\% vs $27.1 \%$, p value: 0.023 ) and higher mean value of modified Gensini Score (MGS) in subgroup A1 compared to sub-group A2 (64.2 \pm 12.6 vs $30.2 \pm 6.6, \mathrm{P}$ value $<0.001)$. Statistical significant difference between 2 subgroups regarding: incidence of ventricular tachycardia $(26.8 \%$ vs $25.4 \%, \mathrm{P}: 0.527)$, need for mechanical ventilation $(39 \%$ vs $27.1 \%, \mathrm{P}: 0.11)$, the duration of ICU stay $(7.3 \pm 2.2$ days versus of the operator and based on the lesion length. There was no statistical significant difference between the 2 subgroups regarding the site of LAD occlusion whether proximal in 20 patients in subgroup A1 $(48.8 \%)$ and in 29 patients in subgroup A2 $(49.2 \%)$ or mid-part in 21 patients in subgroup A1 $(51.2 \%)$ and in 30 patients in subgroup A2 (50. 8\%).Procedural success (achieving TIMI III flow with residual diameter stenosis 620\%) was achieved in all patients. The mean value was Troponin I (ng/mc) 25.00 \pm 0.00 . There was no statistical significant difference regarding the time of resolution of ST segment elevation (i.e. resolution $>70 \%$ ) following the undergone PCI in the 2 subgroups $(90 \pm 20 \mathrm{~min}$ versus $88 \pm 26$, p value 0.44 ) Regarding the supply of the inferior wall, there was no statistical significant difference between the 2 subgroups as follows: In subgroup B1: inferior wall was supplied by RCA in A2 patients $(51.2 \%)$, LCX in 10 patients $(24.4 \%)$ and both RCA and LCX (co-dominance) in 10 patients $(24.4 \%)$. In subgroup A1: inferior wall was supplied by RCA in 31 patients $(52.54 \%)$, LCX in 14 patients $(23.73 \%)$ and both RCA and LCX (co-dominance) in 14 patients $(23.73 \%)$. (P-value: 0.89$)$. Regarding the supply of the LV apex, we found no statistically significant difference between the two subgroups as follows: In subgroup A1: LV apex was supplied by LAD in 37 patients (90.2\%), PDA in 2 patients $(4.9 \%)$ and from both LAD and PDA in 2 patients $(4.9 \%)$. There was no statistically significant difference between the two subgroups (B1 \& B2) regarding demographic data, risk factors for coronary artery disease or any other co-morbidities. We did not find any statistical significant difference between the 2 subgroups B1\&B2 regarding either pain to balloon time $(68 \pm 24$ versus $67 \pm 26 \mathrm{~min}$, $\mathrm{p}$ value $0.82)$ or door to balloon time $(35 \pm 14$ versus $34 \pm 15$ min, $\mathrm{p}$ value 0.9). Echocardiographic assessment of group B patients revealed that mean EF was significantly lower in subgroup B1 compared to subgroup B2 $(47 \%$ vs $60 \%, \mathrm{P}$ value $<0.001)$. Echocardiographic evidence of regional wall motion abnormalities (RWMAs) in inferior segments was found in all patients in the 2 subgroups whereas RWMAs in areas of the left ventricle remote from the infarction were seen in the 2 subgroups (B1\&B2) with no statistical difference ( $20 \%$ versus $24 \%$, p value 0.34). All patients in group B were subjected to 
Magfur Rahman et al; Sch J App Med Sci, Feb, 2021; 9(2): 283-290

undergone PCI of the culprit vessel (RCA in $80 \%$, LCX in 20\%). Each patient included in the two subgroups received a single stent, the length of the stent was selected according to the discretion of the operator and based on the lesion length. There was no statistical significant difference between the 2 subgroups regarding the site of occlusion within the culprit vessel (whether RCA or LCX) as it was proximal in all patients in either sub-group. Procedural success was achieved in all patients. There was no statistical significant difference between the 2 subgroups regarding the time of resolution of ST segment elevation (i.e. resolution $>70 \%$ ) following the undergone PCI $(60 \pm 18$ min versus $55 \pm 21$, p value 0.28 ). The supply of the inferior wall was similar in the two sub-groups (RCA in 40 patients in each subgroup and LCX in 10 patients in each subgroup). Regarding the supply of the LV apex, we found no statistically significant difference between the two subgroups as follows:

Table-2: Acute inferior wall myocardial infarction (group B) data $(\mathbf{n}=200)$

\begin{tabular}{|c|c|c|c|}
\hline Parameter & $\begin{array}{l}\text { Subgroup B1 (with } \\
\text { anterior RSTD) }\end{array}$ & $\begin{array}{l}\text { Subgroup B2 (No } \\
\text { anterior RSTD) }\end{array}$ & $P$ value \\
\hline & (50 patients) & (50 patients) & \\
\hline Age & $50.2 \pm 18.1$ & $53.2 \pm 12.9$ & 0.211 \\
\hline Male $(\%)$ & $72 \%$ & $68 \%$ & 0.106 \\
\hline Diabetes mellitus & $34 \%$ & $32 \%$ & 0.822 \\
\hline Hypertension & $26 \%$ & $24 \%$ & 0.794 \\
\hline Family History of CAD & $22 \%$ & $24 \%$ & 0.802 \\
\hline Dyslipidemia & $38 \%$ & $54 \%$ & 0.079 \\
\hline Cigarette smoking & $64 \%$ & $70 \%$ & 0.32 \\
\hline History of CVA & $6 \%$ & $8 \%$ & 0.52 \\
\hline History of renal impairment & $10 \%$ & $12 \%$ & 0.48 \\
\hline History of chest disease & $20 \%$ & $28 \%$ & 0.29 \\
\hline \multicolumn{4}{|l|}{ Echocardiography: - } \\
\hline $\mathrm{EF} \%$ & $47 \pm 4$ & $60 \pm 3$ & $<0.001$ \\
\hline \multicolumn{4}{|l|}{ Cardiac biomarkers: } \\
\hline Troponin I(ng/mL) & $26.3 \pm 10.6$ & $12.4 \pm 8.9$ & 0.018 \\
\hline \multicolumn{4}{|l|}{ Angiographic data: } \\
\hline Lesion length & $18 \pm 6$ & $16 \pm 7$ & 0.56 \\
\hline Percent stenosis & $95 \pm 5$ & $90 \pm 5$ & 0.22 \\
\hline TIMI III post PCI & $100 \%$ & $100 \%$ & NS \\
\hline Acute stent thrombosis & $0 \%$ & $0 \%$ & NS \\
\hline TLR & $0 \%$ & $0 \%$ & NS \\
\hline Multivessel disease & $60 \%$ & $20 \%$ & $<0.001$ \\
\hline Significant LAD lesions & $78 \%$ & $24 \%$ & $<0.001$ \\
\hline MGS & $36.2 \pm 10.6$ & $20.4 \pm 4.2$ & $<0.001$ \\
\hline \multicolumn{4}{|l|}{ Outcome data: } \\
\hline MAP & $84.8 \pm 17.1$ & $85 \pm 19.3$ & 0.89 \\
\hline Need for vasopressor & $34 \%$ & $32 \%$ & 0.822 \\
\hline Need for MV & $24 \%$ & $22 \%$ & 0.802 \\
\hline Brady arrhythmia & $16 \%$ & $14 \%$ & 0.794 \\
\hline Ventricular tachycardia & $30 \%$ & $28 \%$ & 0.92 \\
\hline ICU stay (days) & $7.4 \pm 3$ & $6.2 \pm 3.1$ & 0.325 \\
\hline
\end{tabular}

Table-3: Acute Inferior Wall myocardial infarction $(n=200)$

\begin{tabular}{|l|l|l|l|}
\hline \multicolumn{5}{|l|}{ Outcome Data: } \\
\hline Mean arterial pressure(MAP) & $91.8 \pm 20.6$ & $103.4 \pm 17.6$ & $<0.001$ \\
\hline Need for vasopressor & $78 \%$ & $33.9 \%$ & $<0.001$ \\
\hline Brady arrhythmia & $48.8 \%$ & $25.4 \%$ & 0.025 \\
\hline Ventricular tachycardia & $26.8 \%$ & $25.4 \%$ & 0.527 \\
\hline Mechanical ventilation & $39 \%$ & $27.1 \%$ & 0.11 \\
\hline Duration of ICU stay days & $7.3 \pm 2.2$ & $5.5 \pm 1.6$ & 0.08 \\
\hline
\end{tabular}

In subgroup B1: LV apex was supplied by LAD in 40 patients $(80 \%)$, PDA in 2 patients (4\%) and from both LAD and PDA in 8 patients (16\%). In subgroup B2: LV apex was supplied by LAD in 39 patients $(78 \%)$, PDA in 3 patients $(6 \%)$ and from both LAD and PDA in 8 patients $(16 \%)$. (P value: 0.78$)$. The 
incidence of multivessel disease was significantly higher in subgroup B1 (60\% vs $20 \%$, P value < 0.001$)$. Significant LAD lesions were significantly higher in subgroup B1compared to the subgroup B2 (78\% vs $24 \%, \mathrm{P}$ value $<0.001)$. Also, the mean value of MGS was significantly higher in subgroup B1 compared to subgroup B2 $(36.2 \pm 10.6$ vs $20.4 \pm 4.2, \mathrm{P}$ value < $0.001)$. In a multivariate analysis, the presence of reciprocal ST segment depression (p 0.02) and impaired LV systolic function ( $\mathrm{p}$ 0.042) were independently correlated with the presence of multivessel coronary artery disease shows (Table-2). In a multivariate analysis, the presence of D.M (p 0.02), reciprocal ST segment depression ( $\mathrm{p}$ 0.01) and impaired LV systolic function ( $\mathrm{p}$ 0.034) were independently correlated with the presence of multivessel coronary artery disease. Concerning the in-hospital outcome, subgroup A1 showed a statistically significant lower mean arterial pressure $(91.8 \pm 20.6 \mathrm{mmHg}$ vs $103.4 \pm 17.6, \mathrm{P}<$ $0.001)$, higher need for vasopressor use (78\% vs $33.9, \mathrm{P}$ value $<0.001)$, higher incidence of Brady arrhythmias ( $48.8 \%$ vs $25.4 \%$, $\mathrm{P}$ value 0.025$)$ yet there was no5.5 \pm 1.6 days, $P$ value: 0.08$)$ or the in-hospital death $(9.76 \%$ versus $10.17 \%$, p value 0.72 ) (Table-3).

\section{DISCUSSION}

The significance of reciprocal ST segment depression during the early phases of acute myocardial infarction has been an area of debate, whether it is a sign of multivessel disease, ischemia at a distance and poor prognosis or merely a benign electrical phenomenon $[9,11]$. We aimed at evaluation of the relevance of reciprocal ST segment depression in patients with acute inferior \& anterior myocardial infarction as regards the left ventricular systolic function $\&$ the extent of coronary artery disease. The current study was conducted as a prospective controlled single center study on 200 patients who were diagnosed as having STEMI (anterior or inferior) \& admitted to the National Institute of Cardiovascular Diseases and Hospital, Dhaka, Bangladesh Echocardiographic assessment was performed for the whole studied patients, we found that patients presented with reciprocal ST segment depression (whether with anterior or inferior STEMI) showed a statistically significant lower mean ejection fraction when compared to those patients without RSTD (37\% vs $53 \%, \mathrm{P}<$ 0.001 in anterior STEMI group) \& (47\% vs $60 \%, \mathrm{P}<$ 0.001 in inferior STEMI group), this goes hand in hand with the data published by Zoghi et al., (studied one hundred eighty-eight patients with acute inferior MI who received thrombolytic therapy as the reperfusion therapy), they concluded that those patients presented with RSTD in non-infarcted leads show a statistically significant lower mean ejection fraction $(49 \% \pm 19 \%)$ compared to those who presented without such RSTD $(52 \pm 15 \%)(\mathrm{P}$ value < 0.001) [12]. Also, Parale et al., (study on 300 patients of acute myocardial infarction 180 anterior \& 120 inferior) concluded that: anterior STEMI patients without reciprocal changes in the inferior leads have a better LVEF \& patients with inferior STEMI with ST segment depression in apicolateral leads have higher prevalence of significant LV dysfunction [1]. Similarly, Gibelin et al., found that the persistence of ST segment depression in noninfarcted leads in inferior STEMI for $>48 \mathrm{~h}$ was associated with a more severe depression of the left ventricular ejection fraction $\&$ that the group presented with RSTD showed a significantly lower EF compared to those presented without RSTD $(52.2 \pm 6 \%$ vs $59.2 \pm$ $7 \%, \mathrm{P}$ value < 0.005) [13]. Discordant to our results, Celik \& his colleagues (studied patients with a first inferior wall myocardial infarction) concluded that there was no statistical significant difference between those patients presented with RSTD \& those without RSTD as regards the ejection fraction, in addition, they concluded that RSTD during early phases of inferior infarction is an electrical reflection of undergone ST segment elevation in the area of infarction [14], the discrepancy between their results \& ours could result from the difference in the number of studied patients (48 patients in their study \& 200 patients in our study), also the difference in the clinical settings (inferior MI in their study in comparison to both anterior \& inferior MI in our study). The postulation that patients with acute MI who presented with RSTD in the non-infarcted leads have higher incidence of multivessel coronary artery disease was proved in the current study which revealed that patients with acute MI (whether anterior wall or inferior wall) who presented with RSTD show a statistically significant higher incidence of multivessel $\mathrm{CAD}$ on their coronary angiograms compared to those who presented without RSTD (80.5\% vs $49.2 \%$ respectively, $\mathrm{P}<0.001$ in anterior MI) \& $(60 \%$ vs $20 \%$ respectively, $\mathrm{P}<0.001$ in inferior $\mathrm{MI})$. This conclusion was concordant with that stated by Zoghi et al., they found that multivessel CAD was present in $58 \%$ of patients with RSTD \& $40 \%$ of patients without RSTD (P: 0.02) [12], Parale et al., concluded that patients of acute inferior wall myocardial infarction with RSTD in apicolateral leads have more occurrence of multivessel disease, however those with acute anterior wall MI with RSTD showed a higher incidence of multivessel disease yet with no statistical significance [1] (the lack of the statistical significance in their study could be explained by the fact that only 12 patients undergone coronary angiography out of total 110 patients presented with anterior wall MI \& reciprocal ST-T changes in inferior leads, so they could reach statistical significance of this subset of patients if a higher pro-portion of the studied patients were subjected to coronary angiography, in our study all the studied patients were subjected to coronary angiography). Contrary to our results, Quyyimi AA et $a l .$, in a study of controlled coronary occlusion during angioplasty, stated that reciprocal change is not common in patients with multivessel disease than in those with single vessel disease [15].We found a statistically significant higher incidence of significant RCA \& CX lesions in those patients with Acute anterior MI \& inferior RSTD compared to those without RSTD 
\& similarly higher incidence of significant LAD lesions in those patients with acute inferior MI \& anterior RSTD compared to those without RSTD, this result goes hand in hand with that published by Hakim et al., who stated that the presence of RSTD in pre-cordial leads during inferior STEMI was associated with more frequent left coronary artery disease [16]. The extent of coronary artery disease was assessed in the current study using the modified Gensini score [8], our data revealed that comparing those patients with RSTD \& those without RSTD in the Anterior MI group revealed $(64.2 \pm 12.6$ vs $30.2 \pm 6.6, \mathrm{P}$ value $<0.001) \&$ in the inferior MI group $(36.2 \pm 10.6$ vs $20.4 \pm 4.2$, P value < $0.001)$. This conclusion obviously revealed that the presence of RSTD was associated with increased extent of coronary artery disease $\&$ are in an agreement with Hakim K \& Co-Workers who demonstrated a significant positive linear correlation between the presence of reciprocal ST segment depression in noninfarcted leads \& gensini score $(r=0.68, \mathrm{P}<0.05)$ [16]. We did not find any statistically significant impact of the site of coronary artery occlusion (i.e. LAD) in anterior STEMI group on the presence of reciprocal ST segment depression. Discordant to our results those stated by Noriega et al., who concluded that only the proximal LAD occlusion in anterior STEMI patients resulted in reciprocal ST-segment depression in leads II, III, and aVF ( $\mathrm{p}<0.001)$. However, in inferior STEMI group in our study, the occlusion was proximal in all patients (whether RCA or LCX occlusion) in either subgroup, so actually we could not assess the impact of the site of coronary artery occlusion on the presence of reciprocal ST segment depression. Birnbaum and his colleagues concluded that in inferior wall myocardial infarction, patients with maximum ST depression in leads V1 to V3 less often had proximal right coronary artery occlusion $(23.9 \%)$ than those patients without precordial ST depression (35.2\%) [7], yet in a recent study carried by Noriega FJ and his colleagues, they concluded that proximal and mid-distal occlusion of RCA or LCX coronary artery always induce STsegment elevation in leads II, III, and aVF and reciprocal ST-segment depression in leads V2 and V3.i.e.reciprocal ST segment depression in inferior STEMI might occur with any segment occlusion in RCA or LCX [17].

\section{CONCLUSION}

Reciprocal ST Segment depression in noninfarcted leads within the setting of acute infarct (anterior or inferior) was related to $\mathrm{LV}$ systolic dysfunction and extent of arterial blood vessel involvement. ST segment depression in acute myocardial infarction Reciprocal was associated with significant LV systolic dysfunction \& coronary artery disease of greater extent.

\section{REFERENCES}

1. Parale GP, Kulkarni PM, Khade Sk, Swapna A, Amit V. Importance of reciprocal leads in acute myocardial infarction. JAPI. 2004; 52:376-9.

2. Edmundo JN, Camara MD, Nisha Chandra MD, Pamela Ouyang MD, Sheldon H, Gottlieb MD, Shapiro Edward P. Reciprocal ST change in acute myocardial infarction: assessment by electrocardiography and echocardiography. J Am Coll Cardiol. 1983; 2:251-7.

3. Becker R, Alpert J. Electrocardiographic ST segment depression in coronary heart disease. Am Heart J. 1988; 115:862-8.

4. Arbane M, Goy JJ. Prediction of the site of total occlusion in the left anterior descending coronary artery using admission electrocardiogram in anterior wall acute myocardial infarction. Am J Cardiol. 2000; 85:487-91.

5. Birnbaum Y, Sclarovsky S, Mager A, Strasberg B, Rechavia E. ST segment depression in aVL: a sensitive marker for acute inferior myocardial infarction. Eur Heart J. 1993; 14:4-7.

6. Peterson ED, Hathaway WR, Zabel KM, Pieper KS, Granger CB, Wagner GS, Topol EJ, Bates ER, Simoons ML, Califf RM. Prognostic significance of precordial ST segment depression during inferior myocardial infarction in the thrombolytic era: results in 16,521 patients. Journal of the American College of Cardiology. 1996 Aug 1;28(2):305-12.

7. Birnbaum Y, Wagner GS, Barbash GI, Gates K, Criger DA, Sclarovsky S, Siegel RJ, Granger CB, Reiner JS, Ross AM. Correlation of angiographic findings and right (V1 to V3) versus left (V4 to V6) precordial ST-segment depression in inferior wall acute myocardial infarction. The American journal of cardiology. 1999 Jan 15;83(2):143-8.

8. Gensini GG. A more meaningful scoring system for determining the severity of coronary heart disease. Am J Cardiol. 1983; 51(3):606.

9. Mirvis DM. Physiologic bases for anterior ST segment depression in patients with acute inferior wall myocardial infarction. Am Heart J. 1988; 116:1308-22.

10. Little WC, Rogers EW, Sodiums MT. Mechanisms of anterior ST segment depression during acute inferior myocardial infarction. Ann Intern Med. 1984; 100:226-9.

11. Wasserman AG, Ross AM, Bogaty D. Anterior ST segment depression during acute inferior myocardial infarction: evidence for the reciprocal change theory. Am Heart J. 1983; 105:516-20.

12. Zoghi M, GüRGüN C, Yavuzgil O, Türkoğlu I, Kültürsay H, Akilli A, Akin M, Türkoğlu C. The angiographic correlation between ST segment depression in noninfarcted leads and the extent of coronary artery disease in patients with acute inferior myocardial infarction: a clue for multivessel disease. The Canadian journal of cardiology. 2003 Jan 1;19(1):67-71. 
Magfur Rahman et al; Sch J App Med Sci, Feb, 2021; 9(2): 283-290

13. Gibelin P, Gilles B, Baudouy M, Guarino L, Morand P. Reciprocal ST segment changes in acute inferior myocardial infarction: clinical, hemodynamic and angiographic implications. Eur Heart J. 1986; 7(2):133-9.

14. Celik S, Yilmaz R, Baykan M, Orem C, Erdol C. Are reciprocal changes a consequence of "ischemia at a distance" or merely a benign electrical phenomenon? A pulsed wave tissue Doppler echocardiographic study. Ann Noninvasive Electrocardiol. 2003; 8(4):302-7.

15. Quyyumi AA, Crake T, Rubens MB, Levy RD, Rickards AF, Fox KM. Importance of "reciprocal" electrocardiographic changes during occlusion of left anterior descending coronary. Lancet. 1986; 1:347-50.

16. Karapınar H, Yanartaş M, Karavelioğlu Y, Kaya Z, Kaya H, Pala S, Emiroğlu MY, Yılmaz A. Importance of reciprocal ST segment depression in the extensive coronary artery disease. European
Journal of General Medicine. 2010 Jan 1;7(1):8891.

17. Noriega FJ, Vives-Borrás M, Solé-González E, García-Picart J, Arzamendi D, Cinca J. Influence of the extent of coronary atherosclerotic disease on ST-segment changes induced by ST elevation myocardial infarction. The American journal of cardiology. 2014 Mar 1;113(5):757-64.

18. Julian DG, Cowan JC. Cardiology. Coronary heart disease -clinical manifestations. 6th ed. London: ELBS publications, B Tindall. 1992; 24: 105-135

19. Goldschlager N, Goldman MJ. Principles of clinical electro- cardiography 13th ed. East Norwalk: Lang e medical book; prentice hall international INC. 1989; 12-12

20. Dewhurst NG, Muir AL. Clinical significance of "reciprocal" ST segment depression in acute myocardial infarction relative contributions of infarct size and ischemia at a distance. The American journal of medicine. 1985 May 1;78(5):765-70. 